Dosier: Paradigma Post-religional - Editorial (c) $(1) \Theta$

\title{
Paradigma post-religional: \\ entre una crisis y una buena noticia
}

Post-religional paradigm: between a crisis and a good news

Paradigma pós-religional: entre crise e boa notícia

José Maria Vigil*

Lo post-religional... ¿qué significa eso? No son pocos los que preguntan. La palabra y el concepto son nuevos, pero no son más que un intento más por nombrar y por entender de forma nueva una realidad más o menos antigua, que está ahí hace tiempo, entre amenazante y misteriosa, desafiante y rebelde, a la espera de encontrar una configuración más precisa en nuestros análisis. Y no es fácil, sobre todo si queremos encontrar una explicación global y segura...

En este mundo religioso actual los signos religiosos más diversos, incluso contradictorios, por lo que darían pie para los diagnósticos más dispares. En efecto, se puede decir que la religión está creciendo, como que está transformando, y que está disminuyendo: las tres cosas son verdad, y las tres pueden ser contradichas. En este caótico mundo de la sociedad humana, con su dinamismo, el aumento de la comunicación, la fecundación mutua en este ámbito "noosférico"... sucede de todo. También en el plano religioso. La aparición y el desarrollo de lo "post-religional" no es la "única cosa que sucede, ni tal vez lo principal de lo que sucede, ni mucho menos es lo que lo explicaría todo lo demás. Pero es una transformación grave que está ahí, que no se puede negar, aunque suscite reacciones muy diferentes y hasta contradictorias en el amplio abanico de la sociedad religiosa actual. Veamos.

\footnotetext{
* Doutor em Educação, com ênfase en los nuevos paradigmas (Universidade La Salle de San José, Costa Rica), pós-doutorado em Ciências da Religião (PUC Minas). Estudou Teologia em Salamanca e Roma, e Psicologia em Salamanca, Madrid e Managua. País de origem: Nicarágua. E-mail: ComisionTeologica@Latinoamericana.org.
} 
Si comenzamos a mirar en la base de la sociedad, es ahí quizá donde más activa está dicha transformación, aunque de un modo totalmente silencioso y no reflexionado. Son verdaderas multitudes las que se ven afectadas: las personas, en todas partes -especialmente en la juventud- sienten y viven lo religioso de una nueva: más secular, más laica, con un cierto desapego o indiferencia. Lo religioso -ritos, creencias, prácticas, dogmas... por ejemplo-, es sentido con un significado cada vez menor, o más extraño, menos plausible, como si fuese de otros tiempos. Esta experiencia se da en los varios niveles junto con las experiencias contrarias, no olvidemos-; se da en la sociedad civil, donde los "sin afiliación religiosa" -en palabras del PEW Center- o "los sin religión" -en palabras del IBGE brasileño- alcanzan cada año un porcentaje superior: algo nunca visto, como el $16 \%$ de la humanidad que han llegado a ser en la actualidad. En Occidente y en el Primer Mundo el gran contingente de estos no afiliados o sin religión está compuesto por personas que salieron de las religiones establecidas, incluido ahí el cristianismo en una medida muy significativa. Pero incluso los personas practicantes, que permanecen en la base de las instituciones, no dejan de experimentar una transformación "postreligional" en su religiosidad. El fenómeno es lento y sutil, pero casi universalmente observado.

En el plano institucional, la situación es muy diferente: las religiones ofrecen resistencia positiva a esta perspectiva. A pesar de que observan este fenómeno en sus filas, no lo incorporan a su agenda, ni introducen su estudio en los asuntos académicos. Es bastante lógico y comprensible, porque en su impresión de lo "post-religional" está conectado psicológicamente con la negatividad del final de la religión. Las instituciones religiosas tienen dificultades para superar ese aspecto negativo de lo post-religional; lo miran como si fuera su propio harakiri; no logran ver lo que lo post-religional les trae de posibilidad de cambio, de "reinicio", de resurrección. Incluso la teología, la vinculada con la institución, tiene dificultades para asumir el tema; no en vano, pues lo "post-religional" postularía una re-lectura competa del campo teológico.

Pero en las ciencias de la religión y el pensamiento libre en general, el tema está ahí, minoritario ciertamente, pero claramente percibido, y exhibiendo 
un atractivo creciente. Basta visitar las librerías y revistas especializadas, o la nueva biblioteca mundial, internet, para ver claramente el crecimiento de un nuevo pensamiento, cada vez más serio y mejor trabajado. Why Christianity Must Change or Die, Hacia una espiritualidad laica, The Death of Religion and the Rebirth of the

Spirit, Christianity After Religion, Otro cristianismo es posible, A New Christianity for a New World, Aunque no haya un Dios ahí arriba, Emergence Chrsitianity... son sólo algunos títulos entre los muchos que están en este mismo momento en el escaparate de esta biblioteca virtual mundial. Ya comienza pues a ser abundante la reflexión elaborada sobre este nuevo tema de lo post-religional.

Como hemos dicho: lo post-religional no es el único fenómeno que está siendo reflexionado, no es la única explicación para lo que está sucediendo, pero esa reflexión que avanza en profundidad y madurez, merece concitar la atención de las religiones y de la teología.

A pesar de lo dicho, hay que reconocer que esa reflexión se encuentra todavía en una primera etapa de desarrollo. Las grandes preguntas sobre la comprensión global del fenómeno todavía están esperando una visión más integral que pueda dar razón cabal de lo pos-religional. No tenemos una teoría completa, una "teoría del todo" que pueda dar esa razón global del hecho. En los hechos cotidianos de la vida religiosa de la gente lo post-religional es fácilmente observable; lo que no nos cuesta capturar es el significado profundo, o más bien, el significado largo y amplio del fenómeno. $\mathrm{Y}$ hay muchas perspectivas nuevas que esperan ser desarrolladas, veamos.

Desde el filón de las ciencias de la Tierra y de la Vida -dentro del cual todo queda cada día más "oiko-centrado", es decir, más contemplado desde la perspectiva del desarrollo de la Madre-Tierra, que involucra lo material con lo espiritual-, lo post-religional se entenderá como un nuevo estadio hacia el que caminamos. En el ámbito interno de las religiones puede y debe decirse muchas cosas sobre lo post-religional, pero son cosas que no contradirán lo que puede decirse desde esta visión centrada en las ciencias de la Tierra y de la Vida. Lo 
post-religional no sería un sencillo fenómeno localizado en el nivel micro de la situación actual de las religiones, sino algo situado en un entorno más amplio, en el nivel mismo de evolución de la Tierra y de la Humanidad. Lo postreligional no sería un problema de las religiones, sino que tendría que ver con la evolución de la vida en la Tierra, así como con la transformación de la humanidad, con el proceso de la evolución humana, ila hominización! El Homo sapiens está creciendo, evolucionando, transformándose y, concretamente en este momento, intensifica su tránsito hacia un nuevo nivel de conciencia. Estamos cruzando el umbral de ese nuevo nivel de la vida humana y de la conciencia, y por eso, las viejas formas religiosas que nos acompañaron durante la etapa que está concluyendo, se marchitan, van a ser dejadas caer, y serán abandonadas en favor de otras que sean adecuadas a esta nueva etapa. Queda mucho por caminar y profundizar por este filón...

El campo de la epistemología también está haciendo su aportación propia, bien interesante. La nueva epistemología testifica que se esta dando un cambio radical: la epistemología mítica, aquella antigua forma -incluso ancestral- como funcionaba el conocimiento humano dentro de las religiones agrarias del período neolítico -el período en el que se formaron las que hoy conocemos como las grandes religiones- ha caducado. Ahora quedó reservada fundamentalmente para la creación literaria, y usos similares, pero ya no es aceptada dentro del campo de las necesidades fundamentales de sentido del ser humano moderno (subrayemos lo de "moderno", pues para el ser humano premoderno, por ejemplo, sigue siendo válida en la actualidad). Resulta que la epistemología mítica fue la epistemología fundamental en el proceso de formación de las religiones, y hasta la fecha no ha sido reemplazada. He aquí una de las razones del malestar que siente la cultura moderna frente a las religiones, que se expresa, entre otras manifestaciones, en ese gran exilio postreligional.

Resurge el concepto antropológico-cultural acuñado por Karl Jaspers como "tiempo axial". De la conciencia religiosa que surgió en aquel primer tiempo axial hemos vivido todo el tiempo que ha transcurrido desde entonces, pero ya no parece capaz de propiciar una nueva configuración espiritual para el 
ser humano. ¿Será que estamos entrando de lleno en un "segundo tiempo axial"? ¿Será eso lo que está por detrás de lo post-religional? El concepto y el término de "segundo tiempo axial" se han vuelto famosos y se encuentran en el centro de la reflexión de punta sobre el tema.

La reflexión y el debate, pues, deben continuar. Con paciencia y actitud pluralista, ya que, como se ha dicho, muchas otras cosas suceden, incluso contrarias, en esta convulsionada noosfera en la que vivimos, crecemos y evolucionamos. En cualquier caso, tenemos que superar esta primera reacción negativa de los prejuicios que el tema plantea en muchos: no es un final de nada, sino sólo de una etapa, que da paso a otra más completa, a un escenario más grande y en un nivel más profundo. Algo pues muy positivo. Lo postreligional no significa el fin de la religión, sino su transformación epocal, en el proceso de la evolución humana; es la aparición de una nueva configuración de la espiritualidad, para esta nueva etapa de la humanidad, para esta nuevo estadio de la conciencia, para esta nueva epistemología, para este nuevo compromiso histórico con la Tierra, con el cosmos, con la naturaleza y con la Vida. Es por eso que el paradigma post-religional, además de tratar de hacernos comprender una crisis... ies también una buena noticia! 